\title{
Analyzing the Centralised Use of Multiple Social Media by Government from Innovations Diffusion Theory Perspective
}

\author{
Enrico Ferro ${ }^{1}$, Euripidis Loukis ${ }^{2}$, Yannis Charalabidis ${ }^{2}$, and Michele Osella ${ }^{1}$ \\ ${ }^{1}$ Istituto Superiore Mario Boella, Via Boggio 61, 10138 Turin, Italy \\ \{ferro, osella\} @ismb.it \\ ${ }^{2}$ University of Aegean, Department of Information and Communication Technologies \\ Engineering, Gorgyras and Palama Str., 83200 Karlovassi, Samos, Greece \\ \{eloukis, yannisx\}@aegean.gr
}

\begin{abstract}
Governments have started increasingly using web 2.0 social media as a new channel of interaction with citizens in various phases of public policies lifecycle. In this direction they have started moving from simpler forms of exploitation of these strong bi-directional communication channels to more complex and sophisticated ones. These attempts constitute important innovations for government agencies, so it is necessary to analyse them from this perspective as well. This paper analyzes an advanced form of centralised use of multiple social media by government agencies from this perspective, using the well established Diffusion of Innovations Theory of Rogers. It is based on a pilot application of the above approach for conducting a consultation campaign in multiple social media concerning the large scale application of a telemedicine program of the Piedmont Regional Government, Italy. It has been concluded that this approach has the fundamental preconditions for a wide diffusion (relative advantage, compatibility with existing values and processes, reasonable complexity, trialability and observability), at least in government organizations having a tradition of bi-directional communication with citizens in all phases of policy making, and also some experience in using social media for this purpose.
\end{abstract}

\section{Introduction}

Governments have started increasingly using web 2.0 social media as a new channel of interaction with citizens in various phases of public policies life-cycle (agenda setting, policy design, adoption, implementation and monitoring - evaluation) [1-5]. Initially they adopted simpler forms of expoitation of these strong bi-directional communication channels, which involved setting up and operating manually accounts in some social media, posting manually content to them and then reading citizens' comments in order to draw conclusions. Recently they tend to shift towards more complex and sophisticated forms of social media use; they are based on the automated posting of content to multiple social media, and also the retrieval of various types of citizens' interactions with it (e.g. numbers of views, likes, retransmissions, etc.) and relevant content, using the Application Progamming Interfaces (APIs) of these social media, and finally highly sophisticated processing of them [6-9]. 
These attempts constitute important innovations for government agencies, so it is necessary to analyse them from this perspective as well. It is important to investigate to what extent they have the fundamental preconditions for a wider diffusion in government. For this purpose we can use methods and frameworks developed by the extensive previous research on innovation diffusion [10]. Such research can reveal both 'strengths and weaknesses' from this perspective, i.e. characteristics and contextual factors that favour diffusion in government, and also characteristics and contextual factors that hinder it, so it can provide guidelines concerning required improvements in relevant systems and methods, and also the contexts they are more suitable for.

This paper makes a contribution in this direction. It analyzes an advanced form of multiple social media use by government agencies, based on a central system that uses social media APIs (a more detailed description of it is provided in section 3), from an innovation perspective, using the well established Diffusion of Innovations Theory of Rogers [11]. Our analysis is based on a pilot application of the above approach for conducting a consultation campaign in multiple social media concerning the large scale application of a telemedicine program of the Piedmont Regional Government, Italy. This research has been conducted as part of project PADGETS ('Policy Gadgets Mashing Underlying Group Knowledge in Web 2.0 Media' www.padgets.eu), supported by the 'ICT for Governance and Policy Modeling' research initiative of the European Commission.

The paper is organized in seven sections. In the following section 2 the background of this study is outlined. It is followed by a brief description of the abovementioned advanced form of social media use in government in section 3, and its pilot application in section 4 . Then in section 5 the research methodology is described, while in the following section 6 the results are presented. The final section 7 contains conclusions and future research directions.

\section{Background}

\subsection{Social Media in Government}

As mentioned in the introduction, social media, though they were initially used mainly by private sector firms in their marketing and customer service activities, are increasingly adopted and utilised by government agencies. It is gradually recognised that social media offer to government agencies significant opportunities for: i) increasing citizens' participation and engagement in public policy making, by providing to more groups a voice in discussions of policy development, implementation and evaluation; ii) promoting transparence and accountability, and reducing corruption, by enabling governments to open up large quantities of activity and spending related data, and at the same time citizens to collectively take part in monitoring the activities of their governments; iii) public services co-production, by enabling government agencies and the public to develop and design jointly government services; iv) crowdsourcing solutions and innovations, by exploiting public knowledge and talent in order to develop innovative solutions to the increasingly complex societal problems [3,12-14]. 
Highly useful for public policy making can be the capabilities offered by social media to apply the 'crowdsourcing' ideas [15,16], which have been initially developed in the private sector, but have subsequently taken root in the public sector as well (with appropriate adaptations to the specificities of government); these Web 2.0 platforms enable government agencies to mine useful fresh ideas from large numbers of citizens concerning possible solutions to social needs and problems, new public services or improvements of existing ones, or other types of innovations [14,17-23]. This can lead to the application of open innovation ideas in the public sector [21], and gradually result in 'co-production' of public services by government and citizens in cooperation [14,17]. According to [19] such 'citizen-sourcing' may change the government's perspective from viewing citizens as "users and choosers" of government services to "makers and shapers" of them.

However, at the same time relevant literature notes that social media not only offer important opportunities to government agencies, but also might pose some risks under specific circumstances [24]. It is widely recognized that further research is required both for developing new advanced and more efficient and effective forms of exploiting the capabilities offered by social media in government, and also for evaluating them from various perspectives in order to understand better their capabilities and strengths on one hand, and their weaknesses and risks on the other $[3,25]$. The research presented in this paper contributes in this direction, focusing on the the evaluation of an advanced form of social media use by government from an innovation diffusion perspective.

\subsection{Diffusion of Innovations Theory}

Extensive research has been conducted on innovation diffusion, in order to understand it better and identify factors that favor it [10]. One of the most widely accepted and use theories of innovations diffusion is the one proposed by [11], which has been extensively employed for analyzing ICT-related innovations in both the public and the private sector [26-29]. According to this theory, there are five critical characteristics of an innovation that determine the degree of its adoption, which are shown with their definitions in Table 1.

Table 1. Innovation characteristics that determine the degree of its adoption

\begin{tabular}{|l|l|}
\hline Characteristic & Definition \\
\hline Relative Advantage & $\begin{array}{l}\text { The degree to which an innovation is perceived as better than } \\
\text { the idea, work practice or object it supersedes }\end{array}$ \\
\hline Compatibility & $\begin{array}{l}\text { The degree to which an innovation is perceived as being } \\
\text { consistent with the existing values, past experiences, and needs } \\
\text { of potential adopters }\end{array}$ \\
\hline Complexity & $\begin{array}{l}\text { The degree to which an innovation is perceived as difficult to } \\
\text { understand, implement and use }\end{array}$ \\
\hline Trialability & $\begin{array}{l}\text { The degree to which an innovation may be experimented with } \\
\text { on a limited scale basis }\end{array}$ \\
\hline Observability & $\begin{array}{l}\text { The degree to which the results of an innovation are visible to } \\
\text { others }\end{array}$ \\
\hline
\end{tabular}


Therefore it is paramount to assess to what extent various both simpler and advanced proposed approaches to social media usage by government agencies for supporting public policy making have the above characteristics, which result in higher levels of adoption and diffusion.

\section{An Advanced Form of Multiple Social Media Use in Government}

An advanced form of social media exploitation by government is under development in the abovementioned European project PADGETS (for more details on it see [6] and [7]), which is shown schematically in Figure 1. It hinges on the use of a central system for conducting consultation campaigns on a policy-related topic in multiple social media, carefully selected so that each of them attracts a different targeted group of citizens. In particular, the frontend of this systems allows a policy maker to create a consultation campaign, which includes definition of its topic, the targeted social media and relevant multimedia content (e.g. a short and a longer textual description, images, videos, etc.), termed as 'Policy Gadgets' (or 'Padgets'). The backend of the system using the APIs of these social media is posting to each of them the appropriate subset of this content (e.g. the short text to Twitter, the longer text to Blogger, the video to YouTube), and then retrieves data on citizens' interactions with it (e.g. numbers of views, likes, ratings, comments) from the afore-mentioned social media. Finally these data undergo in the backend three levels of processing in order to extract from them to useful information for policy makers:

1. calculation of various analytics (e.g. numbers of views, likes, ratings, comments, etc., per region, gender, age and education group, for each of the social media and in total),

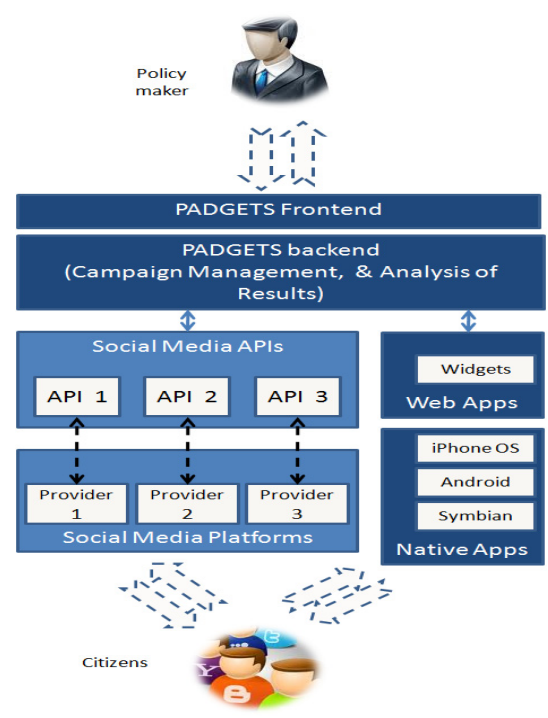

Fig. 1. An advanced form of centrally managed multiple social media use in government 
2. text mining of the textual comments based on opinion mining techniques (for a review of them see [30]), in order to determine the 'sentiment' of citizens' comments (positive or negative), and the main issues and suggestions expressed by them,

3. future projections through simulation (e.g. using system dynamics or agent-based simulation - for more details see [31]).

\section{$4 \quad$ A Pilot Application}

In order to evaluate the abovementioned advanced form of centralised multiple social media use by government agencies from an innovation perspective, a pilot application of it was made in cooperation with Piedmont's Regional Government, Italy. One of its major problems has been for long time its high levels of spending for providing health services to its citizens (on average about $80 \%$ of its total budget). The increasing budget reductions currently experienced at local and at national level require regional governments to face a major challenge: to significantly reduce health related expenditures without deteriorating quality of service. For achieving these conflicting objectives Piedmont's Regional Government examined various measures, one of them being the introduction of telemedicine methods. In this direction it launched a pioneering telemedicine small scale project in one of the least populated and most mountainous of its provinces, Verbano-Cusio-Ossola (VCO). This telemedicine project was supported by the Local Health Authority of VCO that serves a population of about 172,000 citizens, with $23 \%$ of them being over 65 years old. The evaluation of this small scale project was positive, so Piedmont's Regional Government had to decide whether it should proceed to the large scale application of telemedicine practices in the whole Piedmont. Since this was a difficult and complex decision, for which a plethora of factors had to be taken into account, and also due to their long tradition of bi-directional communication with citizens in policy making (mainly using off-line methods, while recently they had some experience in using social media for this purpose), they decided to conduct a consultation with citizens on this in multiple social media, using the approach and the supporting central system described in the previous section. In this way they expected to take advantage of the high penatration of social media (at the level of $30 \%$ of ist population) in this region.

In particular, the objective of this social media campaign was to convey information on the planned extension of the telemedicine initiative in the whole Piedmont region to interested and affected citizens (e.g., patients and their families, doctors, health management emloyees), and then to collect feedback from them. The regional government expected through this campaign to gain a better understanding about the levels of final users' interest in and acceptance of these telemedicine services and the technology mediated model proposed for their provision; also, to identify possible barriers due to practical problems or internal organizational resistance, so that approppriate actions could be taken for addressing them. This project was associated with competences of four different departments of the Piedmont Regional Government, the Public Health, Budget and Finance, Institutional Communication and Regional Innovation ones, so it was decided all of them to be 
involved in it. For this consultation campaign Facebook was used as the central channel, due to both its peculiar interaction patterns as well as its noteworthy penetration rate in Piedmont's population. Beside Facebook, the campaign has made use of Twitter and YouTube. Also, Flickr and LinkedIn assumed an ancillary role. For all these five social media the existing accounts of the Piedmont Regional Goverment were used. The duration of this campaign was one month, during which six videos on telemedicine were created and published in YouTube, and ten policy messages were published via Twitter and Facebook. This campaign was promoted through the websites and the social media accounts of Piedmont Regional Goverment and other local organizations.

\section{$5 \quad$ Research Methodology}

After the end of this consultation campaign an analysis of it was conducted, which included three stages:

1. Initially we examined the analytics of this campaign provided by each of the above social media, with main emphasis on the following:

- for Facebook: impressions per post, unique users per post, engaged users per post, users who generated 'stories' per post (sharings, likes, comments), organic reach per post, viral reach per post, virality percentage per post (number of storytellers divided by reach),

- for YouTube: impressions per video, unique users per video, active interactions per video (likes, dislikes, comments, sharings),

- or Twitter: retweets, replies and mentions, click-throughs on links included in twits.

2. Next we examined the results of the text mining performed for the textual comments of the citizens, with main emphasis on the issues and suggestions it extracted; for each of them we identified and examined the most representative of the comments mentioning it.

3. Finally, two semi-structured interviews were conducted with the most involved senior staff in this pilot: the Head of Public Health Department and a senior member of the Regional Innovation Department. The main objective of these interviews was to assess to what extent the proposed approach (centralised automated use of multiple social media), viewed as an innovation in government agencies policy making processes, has the five preconditions - characteristics for wide diffusion and adoption proposed by the innovations diffusions theory of [11] (in particular, the part of it that deals with the intrinsic characteristics of an innovation that influence an individual's decision to adopt or reject it): relative advantage, compatibility, complexity, trialability and observability. The main questions discussed are shown in Table 2. Each interview lasted about one hour, was tape-recorded and then transcribed. Open coding [32] of interviews transcripts followed, in order to extract the main points. 
Table 2. Main questions of the interviews

To what extent the proposed approach:

- is a better way for consultations with citizens on various public policies than the other existing 'physical' (i.e. through 'physical' meetings) or 'electronic' ways for this (relative advantage)? What are its advantages and also disadvantages?

- is compatible with the values and the policy formulation processes of government agencies (compatibility)?

- can be applied practically by government agencies policy makers without requiring much effort (complexity)?

- can be initially applied in small scale pilot applications by government agencies, in order to assess its capabilities, advantages and disadvantages, before proceeding to a larger scale application (trialability)?

- is an innovation highly visible to other public agencies, policy makers and the society in general, which can create positive impressions and comments (observability)?

\section{$6 \quad$ Results}

\subsection{Citizens' Reach and Engagement}

In terms of reach, the policy messages of this campaign that were posted in the above social media have generated 28,165 impressions. This figure, that has to do with the mere reception of the policy message in the social media realm, is characterized by a cross-platform nature. In Facebook, the figure encompasses the views of posts associated to the campaign which are located on the fan page chosen by the policy makers (we had 27,320 views). Regarding YouTube, here the principle does not change, therefore the indicator includes views of the telemedicine related videos uploaded as part of this campaignv (we had 783). With respect to Twitter it is important to point out that the number of impressions of a given message ("tweet") cannot be computed resorting to either native or third parties' tools. In this platform, the only viable solution has been to estimate impressions using click-throughs on links as well as YouTube referrals (we had 62): as a consequence, this value represents a significant underestimation (at least one order of magnitude) of the actual performance expressed on the specific platform. Translating impressions into unique user accounts, the data from platforms' analytics show that over 11,000 accounts have been reached.

Moving from passive interactions to active engagement, platforms' analytics reveal the participation of more than 300 (unique) individuals during the campaign lifecycle. The inherent cross-platform nature of this consultation campaign implies the use of different measures from each platform for the calculation of this indicator: unique users who generated a story through comments, likes, and public sharing in Facebook, 
unique users who performed actions such as like, dislike, comments and sharing in YouTube and, in Twitter, unique users who re-tweeted or replied to tweets representing policy messages published by the campaign initiator.

As a supplement to afore-mentioned figures, it is relevant to stress that performances exhibited by campaign messages published during the pilot on Piedmont Regional Government's accounts have been remarkably superior to other messages posted in the same period apart from the institutional campaign, which may be seen in the guise of a control group. A quintessential example in this vein has to do with Facebook regional channel: taking into account this platform, the messages of this campaign had a reach three times larger than others (on average), while in terms of active engagement, they generated reactions about twenty times more than usual.

Going beyond reach and engagement numbers, precious stimuli for policy makers derive from the main perceptions, issues and suggestions extracted through text mining of citizens' textual commens. First of all, telemedicine is percived as a useful means for the rationalization of public spending, especially in a period when budget constraints are tighter than ever. Some messages in this vein are as follows:

'The project has very good prospects and it can certainly represent an efficient way to reduce the cost of public health and prevention services'.

'An example to follow for regions like mine, Lazio, where - more and more frequently - past and present spending reviews are leading to closure of hospitals'.

Also, substantial benefits are expected to arise also for the patients: whilst the continuous remote supervision of the patient's conditions is expected to result in an improvement of the quality of healthcare provision and patien's life, a reduction in the number of trips between dwelling places and local hospitals, and will have a remarkable impact in terms of savings (i.e., time devoted to mobility and cost of fuel) and environmental footprint (i.e., containment of $\mathrm{CO} 2$ emissions). For instance, one message remarks that:

'Telemedicine can remarkably reduce the queue for particular clinical examinations whose waiting time has now become eternal'.

However, despite rosy expectations and fervent impulses coming from technophiles, there are still some major roadblocks clearly perceived by the population. In fact, a number of concerns have been expressed about the uneven technological literacy among patients, in light of the relentless aging phenomenon. A message on this states that:

'Technology scares, especially those who are not born with the PC in the cradle'.

Finally, citizens involved in the campaign outlined the risk of applying a technocratic approach that does not take into account the human aspects of the physician-patient relationship, or having problems due to insufficient training of healthcare personnel:

'In any case, data interpretation - especially in more complex situations - requires always a thorough (and human) assessment'. 


\subsection{Innovation Diffusion Determinants Assessment}

The interviewees agreed that this approach (centralised automated use of multiple social media) offers strong relative advantages, in comparison with existing both 'physical' alternatives (e.g. physical meetings for communicating with citizens concerning various public policies under design or implementation) and 'electronic' ones (e.g. government e-participation/e-consultation portals). The inherent nature of this approach is perceived as going beyond the traditional schemes of 'official' eparticipation/e-consultation portals developed and operated by government organizations. It was stressed that such a 'formal' e-consultation gives citizens some opportunities to offer comments in response to a limited set of questions posed by government. However, these designated 'official' e-consultation spaces are largely unknown to the general public due to the high costs of promotion and the slow pace of dissemination. Furthermore the tools they provide are not sufficiently user-friendly, and are often usable only by an affluent and acculturate minority. Another problem is that when the consultation period ends, policy makers are hit by a wave of textual comments, without obtaining a clear picture of vox populi. However, the examined novell approach is perceived as overcoming the above weaknesses and problems. It leverages already established installed large bases of social media users, and paves the way to a friction-less (i.e., faster and more frequent) interaction between policy makers and society. A substantial relative advantage arises with respect to previous generation of e-participation models due to the fact that the government makes a first step towards citizens (moving to the electronic spaces they chose for discussion and content production), rather than expecting the citizenry to move their content production activity onto the 'official' spaces created for e-Participation. It was also mentioned that the high levels of citizens' reach and engagement achieved in this pilot application of the examined approach, and the useful insights offered by citizens ${ }^{\text {* }}$ textual comments and opinions, as discussed in previous section 6.1, are indicative the significant relative advantages that the examined approach provides. In general, the interviewees agree that this pilot confirms the expectations of relevant literature, as mentioned in 2.1, concerning the potential of social media in government along four dimensions: increasing citizens' participation and engagement in public policy making, promoting transparence and accountability (as the main advantages and disadvantages of various policy options can be widely communicated and discussed), public services co-production, and crowdsourcing solutions and innovations.

With respect to compatibility, the interviewees found that the pronounced crosssectoral nature of this approach renders it a precious decision support tool capable to maximize the 'horizontality' in terms of application scope, and, as a consequence, it may be easily and effectively employed for any kind or thematic area of public policy. Furthermore, it can be used in every stage of the policy life-cycle (agenda setting, policy design, adoption, implementation and monitoring and evaluation). As a result, with regard to compatibility, the recourse to multiple social media seems to fit in with the policy formulation processes of government agencies. Interviewees concluded that the whole approach was compatible with the values and policy formulation processes of Piedmont Regional Government. 
However, it was mentioned that the above relative advantages and compatibility are to a significant extent associated with two positive characteristics of the particular government agency, which might not exist in other other contexts: i) their long tradition and culture of bi-directional communication with citizens in all phases of policy making, and ii) their previous familiarity with and experience in using social media for the above purpose. If these do not exist, then it is likely that the above relative advantage and compatibility might be lower, or even there might be important relative disadvantages in comparison with existing alternative channels. Most government agencies have already developed some 'organizational capabilities' in using the abovementioned alternative physical and electronic channels of communication with citizens, but this has not happened yet with social media. The interviewees stressed that a 'typical public servant' might initially not feel 'culturally fit' for and familiar with the language and style of dialogue of most social media, and find it difficult to participate effectively in such dialogues; so if adequate training is not provided to them, there might be a risk of ineffective or even problematic communication between government agencies and citizens in the social media, which would have negative impact on the public image of the former. Furthermore, if there is a lack of tradition and culture of bi-directional communication with citizens in some government agencies, this might become more visible to the citizens due to the extensive, direct and informal interaction that characterises the social media, with negative consequences.

With respect to complexity, it was mentioned that the proposed approach, in combination with the ICT tools supporting it, have the distinctive trait of keeping moderate the cognitive effort required to policy makers. Despite processing data in behind the scene and provide decision makers with a set of synthetic, fresh and relevant data through intuitive visual outputs. The easily understandable way of reporting campaign results determines a substantial simplicity in usage that clears the hurdle of complexity, creating a fertile soil for a smooth adoption by every policymaker inclined to embrace 'open' policy making.

Furthermore, the successful completion of the pilot held in Piedmont Region corroborates the a priori conviction that this approach might take advantage of a noticeable scalability that allows to move all along the continuum ranging from small scale to full scale. All interviewees agreed that this innovation may be experimented without particular obstacles, since there does not exist a 'minimum efficient scale' for running a campaign, so it is characterised by trialability. It was recognised that this approach can be initially applied by government agencies in small scale pilot applications, in order to assess its capabilities and to fine-tune the underpinning mechanisms, before proceeding to larger scale applications.

Finally, the interviewees mentioned that the unprecedented exposure (at least in the digital world) given by social media to public policy campaigns makes this innovation highly visible to other public agencies, policy makers and the society in general. In fact, policy messages make their appearance on public pages accessible by everyone (i.e., Facebook Fan Pages, Twitter Pages, YouTube Channels) and viral 'contagious' phenomena occurring in the social media realm in light of intertwined social connections play their part in garnering a rapid and vast spreading of the policy 
proposal at stake. The resulting observability of the innovation has according to the interviewees a twofold advantage: on one hand, it stimulates the citizenry to step in the debate boosting the adoption rate, and, on the other hand, the opportunity to observe how the tool works on the field can create awareness in the public realm about the opportunity to tap social media in order to let 'collective intelligence' percolate across governmental boundaries.

\section{Conclusions}

The increasing adoption of social media by government agencies, initially simpler but gradually becoming more and more complex and sophisticated, constitutes an important innovation in their public policy making processes. Therefore it is important to analyse it from an innovation diffusion perspective as well, taking advantage of the extensive previous research in this area. This will allow us to understand to what extent various existing or emerging forms of social media exploitation in government, simpler or sophisticated ones, have the fundamental preconditions for a wider diffusion. Also, it will allow identifying characteristics of these approaches and the supporting systems, or of their context (e.g. characteristics of the adopting government organizations or the targeted citizens ' groups), which do not favour their diffusion, and take appropriate actions for addressing them.

This paper aims to make a contribution in this direction. It analyses an advanced approach of using social media by government agencies, which includes centralized combined exploitation of multiple complementary social media platforms, in an automated manner taking advantage of their APIs, initially for posting to them various types of policy-related content, and then for retrieving users' interactions with them in these social media platforms, which finally undergo sophisticated processing. As theoretical foundation for our research we use the Diffusion of Innovations Theory proposed by [11]. Our analysis is based on a pilot application of this approach for conducting a consultation campaign concerning the large scale application of a telemedicine program of the Piedmont Regional Government, Italy.

It has been concluded that this approach has the fundamental preconditions for a wide diffusion according to the above theory: relative advantage, compatibility with existing values and processes, reasonable complexity, trialability and observability. However, its relative advantage and compatibility relies to a significant extent on the context on: i) the history and tradition of the adopting government agency with respect to bi-directional communication with citizens, and ii) on its familarity with and experience in using social media for this purpose. If these do not exist, the relative advantage and compatibility might be lower, or even there might be relative disadvantages in comparison with the alternative physical and electronic channels of communication with citizens. The use of social media by government agencies without sufficient preparation, training of the responsible staff, and in general development of 'organizational capabilities' in this area, and culture of bi-directional communication with citizens, might have negative impact on the image of government agencies. 
The findings of this paper have interesting implications for research and management. With respect to research, it provides a framework for future analysis of existing or emerging forms, systems and methods of social media use by government agencies from an innovation diffusion perspective, which is definitely a quite important one. In general it opens up a new research direction, which combines theories, frameworks and methods from innovation, political sciences and eparticipation research, in order to provide a deeper understanding of social media based innovations in political communication. With respect to management of government agencies, findings indicate that such a complex and sophisticated form of multiple social media use for bi-directional communication with citizens has the fundamental preconditions for a wide diffusion and adoption. However this might depend from previous history and tradition in communication with citizens, and at the same time might necessitate training and familiarization with a new language and style of dialogue with citizens, quite different from the ones dominant previously.

Further research is required on the existing and the emerging more complex and sophisticated forms of social media use in government from various innovation related perspectives, in different contexts (e.g. different government agencies with different cultural - organizational characteristics and relevant experiences, for different types of topics), examining the viewpoints of all stakeholders (politicians, public servants and citizens) and using both qualitative and quantitative methodologies.

\section{References}

1. Osimo, D.: Web 2.0 in Government: Why and How? European Commission Joint Research Center - Institute for Prospective Technological Studies. Office for Official Publications of the European Communities, Luxenbourg (2008)

2. Punie, Y., Misuraca, G., Osimo, D.: Public Services 2.0: The Impact of Social Computing on Public Services. JRC Scientific and Technical Reports. European Commission, Joint Research Centre, Institute for Prospective Technological Studies (2009)

3. Bertot, J.C., Jaeger, P.T., Hansen, D.: The impact of policies on government social media usage: Issues, challenges and recommendations. Government Information Quarterly 29, 30-40 (2012)

4. Bonsón, E., Torres, L., Royo, S., Flores, F.: Local e-government 2. 0: Social media and corporate transparency in municipalities. Government Information Quarterly 29, 123-132 (2012)

5. Snead, J.T.: Social media use in the U.S. Executive branch. Government Information Quarterly 30, 56-63 (2013)

6. Ferro, E., Osella, M., Charalabidis, Y., Loukis, E., Boero, R.: Policy Gadgets: Paving the Way for Next-Generation Policy Making. In: IFIP Third International Conference on eParticipation - ePart 2011, Delft, The Netherlands (2011)

7. Charalabidis, Y., Loukis, E.: Participative Public Policy Making Through Multiple Social Media Platforms Utilization. International Journal of Electronic Government Research 8(3), 78-97 (2012) 
8. Wandhöfer, T., Taylor, S., Alani, H., Joshi, S., Sizov, S., Walland, P., Thamm, M., Bleier, A., Mutschke, P.: Engaging Politicians with Citizens on Social Networking Sites: The WeGov Toolbox. International Journal of Electronic Government Research 8(3), 22-43 (2012)

9. Charalabidis, Y., Triantafillou, A., Karkaletsis, V., Loukis, E.: Public Policy Formulation Through Non-Moderated Crowdsourcing in Social Media. In: Proceedings of IFIP Fourth International Conference on e-Participation - ePart 2012, Kristiansand, Norway, September 3-6 (2012)

10. MacVaugh, J., Schiavone, F.: Limits to the diffusion of innovation - A literature review and integrative model. European Journal of Innovation Management 13(2), 197-221 (2010)

11. Rogers, E.: Diffusion of Innovations, 5th edn. The Free Press, New York (2003)

12. Bertot, J.C., Jaeger, P.T., Munson, S., Glaisyer, T.: Engaging the public in open government: The policy and government application of social media technology for government transparency. IEEE Computer 43(11), 53-59 (2010)

13. Bertot, J.C., Jaeger, P.T., Grimes, J.M.: Promoting transparency and accountability through ICTs, social media, and collaborative e-government. Transforming Government: People, Process and Policy 6(1), 78-91 (2012)

14. Linders, D.: From e-government to we-government: Defining a typology for citizen coproduction in the age of social media. Government Information Quarterly 29, 446-454 (2012)

15. Surowiecki, J.: The wisdom of crowds. Doubleday, New York (2004)

16. Brabham, D.C.: Crowdsourcing as a Model for Problem Solving: An Introduction and Cases. Convergence: The International Journal of Research into New Media Technologies 14(1), 75-90 (2008)

17. Bovaird, T.: Beyond engagement and participation: User and community coproduction of public services. Public Administration Review 67(5), 846-860 (2007)

18. Torres, L.H.: Citizen sourcing in the public interest. Knowledge Management for Development Journal 3(1), 134-145 (2007)

19. Lukensmeyer, C.J., Torres, L.H.: Citizensourcing: Citizen participation in a networked nation. In: Yang, K., Bergrud, E. (eds.) Civic Engagement in a Network Society, pp. 207233. Information Age Publishing, Charlotte (2008)

20. Chun, S.A., Shulman, S., Sandoval, R., Hovy, E.: Government 2.0: Making connections between citizens, data and government. Information Polity 15(1/2), 1-9 (2010)

21. Hilgers, D., Ihl, C.: Citizensourcing: Applying the concept of open innovation to the public sector. The International Journal of Public Participation 4(1), 67-88 (2010)

22. Nam, T.: Suggesting frameworks of citizen-sourcing via Government 2.0. Government Information Quarterly 29, 12-20 (2012)

23. Margo, M.J.: A Review of Social Media Use in E-Government. Administrative Sciences. Administrative Sciences 2(2), 148-161 (2012)

24. Picazo-Vela, S., Gutiérrez-Martínez, I., Luna-Reyes, L.F.: Understanding risks, benefits, and strategic alternatives of social media applications in the public sector. Government Information Quarterly 29, 504-511 (2012)

25. Chun, S.A., Luna Reyes, L.F.: Editorial - Social media in government. Government Information Quarterly 29, 441-445 (2012)

26. Wonglimpiyarata, J., Yuberk, N.: In support of innovation management and Roger's Innovation Diffusion theory. Government Information Quarterly 22, 411-422 (2005)

27. Raus, M., Flügge, B., Boutellier, R.: Electronic customs innovation: An improvement of governmental infrastructures. Government Information Quarterly 26, 246-256 (2009) 
28. Loukis, E., Spinellis, D., Katsigiannis, A.: Barriers to the adoption of B2B e-marketplaces by large enterprises: lessons learnt from the Hellenic Aerospace Industry. Information Systems Management 28(2), 130-146 (2011)

29. Al-Jabri, I.M., Sohail, M.S.: Mobile Banking Adoption: Application of Diffudion of Innovation Theory. Journal of Electronic Commerce Research 13(4), 373-385 (2012)

30. Maragoudakis, M., Loukis, E., Charalabidis, Y.: A Review of Opinion Mining Methods for Analyzing Citizens' Contributions in Public Policy Debate. In: IFIP Third International Conference on e-Participation - ePart 2011, Delft, The Netherlands (2011)

31. Charalabidis, Y., Loukis, E., Androutsopoulou, A.: Enhancing Participative Policy Making Through Simulation Modelling - A State of the Art Review. In: Proceedings of European Mediterranean Conference on Information Systems (EMCIS) 2011, Athens, Greece, May 30-31 (2011)

32. Maylor, H., Blackmon, K.: Researching Business and Management. Palgrave-Macmillan, New York (2005) 